\title{
'My passion for dentistry has only got stronger'
}

\author{
Russell Hashemi, a 2nd Year undergraduate dental student at Plymouth University Peninsula Schools of Medicine \\ and Dentistry (PUPSMD), reflects on his academic journey so far.
}

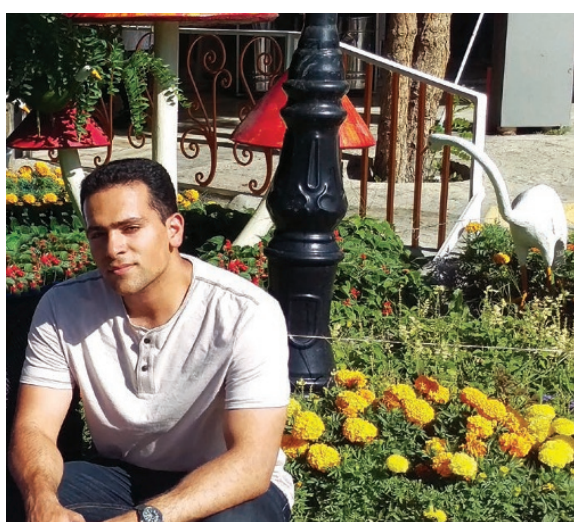

A

t my university, students have patient contact and are able to perform irreversible procedures such as filling teeth from the very first year. This was a very intimidating concept for me prior to starting on the course. I had a number of questions racing through my mind like: is the patient still going to be alive by the end of the appointment? What if my hand slips or I lose control, and end up carving a horrible grin on the patient, making them look like the Joker? Is it too late to switch courses to something less invasive like accounting?

Thankfully I passed my first year with no such casualties, and my passion for dentistry has only got stronger.

I applied to study dentistry because of the way the profession succeeds in interlacing skill sets from art, science and engineering. It is also a very rewarding career path. There are tangible rewards such as an above average salary and the opportunity to own and run a business. There are also intangible rewards such as improving patients' oral health and relieving them of often excruciating pain and changing their lives for the better, providing immeasurable job satisfaction and personal fulfilment in helping others.

My decision to study dentistry in Plymouth posed a number of challenges, the main one being that it would be the first time that I would live away from home and be independent. The long journey from London was also particularly daunting. In spite of these obstacles, I saw it as an opportunity for personal growth and to get out of my comfort zone.

Now a second year student, with hindsight, I'm glad I took the opportunity to study in Plymouth. The city is a great place to live and filled with sociable people, a large percentage of whom are fellow students. The student union is brilliant and there are loads of societies, sports and extracurricular activities to take part in which will help you to meet new people and to fully immersive yourself in life at university.

The dental school delivers a wonderful platform to study and provides lots of amazing opportunities for its students.

As a second year dental student at Plymouth University Peninsula, each day brings its own new set of challenges with it. Whether it's learning about the anatomy of nerve pathways (which are acutely mind numbing) to performing clinical procedures like extractions, there's lots to do with little time to spare.

Perhaps what's been the most difficult, yet rewarding, aspect of the course has been interacting with people. Working on phantom heads is much more straightforward than dealing with actual patients, for example: mannequins don't breathe and fog up your mirror, they don't have an insubordinate tongue which feels the need to push against your instrument making you readjust your finger rest every ten seconds. They don't feel pain when you're doing a filling with no local anaesthetic and they certainly don't have any anxiety or stress about getting into the dental chair. But despite the challenges that real patients pose for us students, in my experience I have found the benefits to far outweigh the drawbacks: speaking to patients, finding out about their lives and getting to know them on a personal level. Helping them to improve their oral health and get the smile they always wanted is something that's incredibly rewarding and personally motivating.

Looking back on my first year on the course, I've gained a lot of knowledge and greatly improved my practical skills since I first held a handpiece. However, I also had some slip-ups along the way, though I found them to be excellent opportunities to learn and further develop my skills. In fact, if I could give one piece of advice to a newly inducted first year student, it would be to not feel the need to rush through your work when seeing a patient or doing a procedure. I remember when I was first taught how to do a Class I cavity preparation, after just our second teaching session, I had this overwhelmingly off-putting voice in my head telling me to 'HURRY UP, in a real practice the filling should be done in ten minutes!' This of course created unwarranted stress and disruption, and meant that in my haste to finish the preparation I would miss certain details such as ensuring smooth walls around the prep, getting the right cavo-surface angles etc. When I would call one of my supervisors over to check my prep, unsurprisingly they would find an area in which my prep had a shortcoming. This was quite demoralising at the time and made me feel like I wasn't cut out to be a dentist. But after speaking to some of the staff and students from senior years, they told me that for the first two years of your course, just focus on mastering the basics, speed will then naturally develop later. By taking this advice on board, my attention to detail has improved substantially, as well as the overall quality of my work. Dental school is hard enough as it is; don't make it harder for yourself?

During my free time I like to work out at the gym. Sitting on a chair for most of the day can be quite taxing for the lower back, which is why I've made exercise a staple of my daily routine. While at the gym I do anything from traditional weightlifting to calisthenics (a form of bodyweight training) and try to make my workouts unconventional to keep me motivated to train. I've got a difficult year ahead of me as the university workload intensifies and keeping up with my training schedule at the same time is going to be tough. But I'm always up for a challenge and I can't wait to continue the journey to becoming a dentist. 